\title{
Variability of renal colic management and outcomes in two Canadian cities
}

\author{
Grant Innes, MD, MHSc ${ }^{*}$; Andrew McRae, MD, PhD*; Eric Grafstein, MD*; Michael Law, $\mathrm{PhD}^{\S}$; \\ Joel M. H. Teichman, MD"; Bryce Weber, MD; Kevin Carlson, MD; Heidi Boyda, PhD*; \\ James Andruchow, MD, MSc ${ }^{*}$
}

\section{CLINICIAN'S CAPSULE}

What is known about the topic?

Most ureteral stones pass spontaneously, but intervention is an option. No trials have compared conservative vs. interventional treatment.

What did this study ask?

We compared 60-day outcomes for ED patients with ureteral colic in Calgary and Vancouver.

What did this study find?

Index intervention rate was seven-fold higher in Calgary. Calgary patients had more subsequent ED revisits and hospitalizations. Adverse outcomes were associated with intervention for small stones and with non-intervention for large stones.

Why does this study matter to clinicians?

Conservative management of small stones and early intervention for large stones may improve system utilization and patient outcomes.

\section{ABSTRACT}

Background: Some centres favour early intervention for ureteral colic while others prefer trial of spontaneous passage, and relative outcomes are poorly described. Calgary and Vancouver have similar populations and physician expertise, but differing approaches to ureteral colic. We studied 60-day hospitalization and intervention rates for patients having a first emergency department (ED) visit for ureteral colic in these diverse systems.

Methods: We used administrative data and structured chart review to study all Vancouver and Calgary patients with an index visit for ureteral colic during 2014. Patient demographics, arrival characteristics and triage category were captured from ED information systems, while ED visits and admissions were captured from linked regional hospital databases. Laboratory results were obtained from electronic health records and stone characteristics were abstracted from diagnostic imaging reports. Our primary outcome was hospitalization or urological intervention from 0 to 60 days. Secondary outcomes included ED revisits, readmissions and rescue interventions. Time to event analysis was conducted and Cox Proportional Hazards modelling was performed to adjust for covariate imbalance.

Results: We studied 3283 patients with CT-defined stones. Patient and stone characteristics were similar for the cities. Hospitalization or intervention occurred in $60.9 \%$ of Calgary patients and $31.3 \%$ of Vancouver patients $(p<0.001)$. Calgary patients had higher index intervention rates $(52.1 \%$ v. $7.5 \%)$, and experienced more ED revisits and hospital readmissions during follow-up. The data suggest that outcome events were associated with overtreatment of small stones in one city and undertreatment of large stones in the other.

Conclusions: An early interventional approach was associated with higher ED revisit, hospitalization and intervention rates. If these events are markers of patient disability, then a less interventional approach to small stones and earlier definitive management of large stones may reduce system utilization and improve outcomes for patients with acute ureteral colic.

\begin{abstract}
RÉSUMÉ
Introduction: Dans certains centres hospitaliers, on préfère les interventions précoces dans le traitement des coliques néphrétiques tandis que, dans d'autres, on préfère les tentatives de passage spontané, mais les résultats relatifs aux deux types de traitement sont peu documentés. Les villes de Calgary et de Vancouver ont des populations comparables et, bien que les médecins aient les mêmes compétences, ils appliquent des approches différentes. Aussi avons-nous étudié les taux d'intervention et d'hospitalisation au bout de 60 jours, selon les deux approches, chez les patients ayant consulté, pour la première fois, un médecin au service des urgences (SU), pour des coliques néphrétiques.
\end{abstract}

From the *Department of Emergency Medicine, University of Calgary, Calgary, AB; †Department of Community Health Sciences, University of Calgary, Calgary, AB; $\ddagger$ Department of Emergency Medicine, University of British Columbia, Vancouver, BC; §School for Population and Public Health, University of British Columbia, Vancouver, BC; ๆDepartment of Urology, University of British Columbia, Vancouver, BC; and ISection of Urology, Department of Surgery, University of Calgary, Calgary, AB.

Correspondence to: Dr. Grant Innes; 781 East 8th Street, North Vancouver, BC, Canada V7L 2A1; Email: Grant.innes@ahs.ca 
Méthode: Nous avons utilisé des données administratives et procédé à un examen structuré des dossiers médicaux de tous les patients ayant consulté, pour la première fois, un médecin, dans les hôpitaux de Vancouver et de Calgary, pour des coliques néphrétiques, en 2014. Les données démographiques ainsi que les renseignements sur les caractéristiques à l'arrivée et les catégories de triage ont été tirés des systèmes d'information des SU, tandis que les renseignements sur les consultations au SU et les admissions ont été tirés des bases de données hospitalières, reliées entre elles au niveau régional. Les résultats des examens de laboratoire provenaient des dossiers médicaux électroniques, et les caractéristiques des calculs, des rapports d'imagerie diagnostique. Le principal critère d'évaluation consistait en I'hospitalisation ou en une intervention urologique rendues nécessaires entre le $1^{\text {er }}$ et le $60^{\mathrm{e}}$ jour. Les critères d'évaluation secondaires comprenaient les reconsultations au SU, les réadmissions et les interventions de rattrapage. Nous avons réalisé une analyse du temps écoulé avant les événements cibles et appliqué le modèle de régression des hasards proportionnels de Cox afin de tenir compte des différences de covariables.

Résultats: Ont été examinés les dossiers de 3283 patients chez qui la présence de calculs a été confirmée par tomodensitométrie. Les caractéristiques relatives aux patients et aux calculs étaient comparables dans les deux villes. II y a eu hospitalisation ou intervention chez $60,9 \%$ des patients à Calgary contre $31,3 \%$ des patients à Vancouver $(p<0,001)$. Les patients à Calgary ont connu un taux plus élevé d'intervention au cours de la consultation de référence $(52,1 \%$ vs. $7,5 \%)$ que ceux à Vancouver, et les premiers ont également reconsulté un médecin au SU ou ont été réadmis plus souvent que les seconds durant le suivi. D'après les données recueillies, les événements liés aux résultats étaient associés à un traitement excessif des petits calculs dans une ville et à un traitement insuffisant des gros calculs dans l'autre.

Conclusions: L'approche interventionnelle précoce était associée à des taux plus élevés de reconsultation au SU, d'hospitalisation et d'intervention. Si ces événements étaient des marqueurs d'incapacité, alors l'approche moins interventionnelle des petits calculs et l'application moins tardive du traitement indiqué des gros calculs pourraient réduire I'utilisation des ressources et améliorer les résultats cliniques chez les patients souffrant de coliques néphrétiques en phase aiguë.

Keywords: renal colic, emergency, management, outcomes

\section{INTRODUCTION}

Renal colic is a high prevalence disorder that affects $10 \%$ of the population. ${ }^{1}$ It is a recurrent condition that causes extreme pain and has a significant impact on quality of life and health system utilization. ${ }^{2-4}$ Guidelines suggest that many patients with an acute stone episode are appropriate for a trial of spontaneous passage that is successful in $60 \%-90 \%$ of cases, ${ }^{5-11}$ but some patients require intervention or hospitalization for control of severe symptoms; however, reported admission rates for acute stone episodes range from $2 \%$ to $13 \% .^{12-18}$ A 2005 US study estimated that acute stone events generated total costs of US\$5.2 billion per year in the employed population alone, with 3.1 million lost workdays. ${ }^{3}$

While the traditional approach is a trial of spontaneous passage, minimally invasive ureteroscopic techniques have made early intervention an option for some patients. ${ }^{19}$ Direct and indirect care costs may be higher with a surgical approach, ${ }^{3,20-22}$ but early intervention has the potential to terminate an episode of renal colic rapidly, decrease patient disability, and reduce the need for subsequent emergency department (ED) or hospital-based care. To date, no studies have compared the outcomes of patients treated medically v. surgically at their index ED visit for an acute stone, and high inter-institutional practice variability reflects this lack of evidence.

The Calgary Health Region and Vancouver Coastal Health Authority are comparable integrated health systems that have differing approaches to acute renal colic. Vancouver physicians typically prescribe a trial of spontaneous passage for acute stone events, and the Calgary practice favours early surgical intervention for most significant stones. ${ }^{23}$ These fundamentally different approaches in comparable health systems provide the opportunity to study system-level outcomes associated with interventional v. conservative management. Our main objective was to compare event rates, defined as the need for hospitalization or surgical intervention within 60 days of the index renal colic visit, in these contrasting care systems.

\section{METHODS}

\section{Design and setting}

We used administrative data supplemented by a structured chart review to study all patients with an ED diagnosis of acute renal colic seen in two Canadian 
health regions during the calendar year, 2014. Calgary has four adult EDs, and Vancouver has five, serving 1.4 million and 1.1 million people, respectively. ${ }^{24,25}$ The cities have similar population demographics, health infrastructure, and access to technology. Both have integrated care delivery systems with centralized leadership, regional program structures, operational processes, quality management, data capture, and information systems. Urologists and emergency physicians in both cities have equivalent training and licensing, as well as maintenance of competence requirements. One key difference is that, in Calgary, urological interventions are performed at a single site, which is also the urological referral and intervention centre for Southern Alberta. These regionally coordinated health systems allowed us to conduct a population-based study of all patients who attended an ED with acute renal colic and assured a low likelihood of missing important outcome events in the study cohorts. The study was approved by the University of British Columbia Clinical Research Ethics Board and the University of Calgary Conjoint Health Research Ethics Board in accordance with Canadian Tri-council guidelines and the Declaration of Helsinki.

\section{Patients}

We identified all patients who attended a Calgary or Vancouver ED during 2014 with an ED diagnosis of renal colic based on the following ICD-10 $\operatorname{codes}^{3,26}$ : calculus of the kidney (N200), calculus of the ureter (N201), calculus of the kidney with calculus of the ureter (N202), hydronephrosis with renal and ureteral calculous obstruction (N132), unspecified renal colic (N23), and unspecified urinary calculus (N209). We focused on patients who had a well-characterized ureteral stone seen on computed tomography (CT), including the assessment of stone size, location, the degree of hydronephrosis, and stranding. We excluded patients with isolated intra-renal stones because these stones are treated using a different management approach. We also excluded patients who had a prior ED renal colic visit within 30 days because our intent was to study incident cases and to exclude patients who had already failed outpatient management. We excluded patients who were referred for direct urology care because they were thought to represent a selected higher complexity group already deemed to require surgical involvement, and we also excluded patients who had out-of-region postal codes, as their follow-up ED visits and hospitalizations could have occurred at hospitals outside the study areas.

\section{Study procedures}

During the study period, there were no renal colic management protocols in place, and the patients were managed at the ED physicians' discretion in both cities. The usual treatment for acute renal colic in Vancouver is a trial of spontaneous passage, and the treatment for most significant stones in Calgary is admission for early surgical intervention, which may involve stone destruction, stone extraction, ureteral dilation, or stenting. This geographic treatment variability provided a unique opportunity to study comparable cohorts of patients in similar health systems exposed to different management strategies.

\section{Data capture}

Patient demographics, arrival mode, presenting complaint, triage category, and index disposition were captured from regional ED clinical databases. ED revisits, hospitalizations, and procedures, as well as ED and inpatient diagnoses, were obtained from the discharge abstract database of the hospitals. To assure inclusion of all relevant Vancouver procedures, the Vancouver Coastal Health Authority (VCHA) regional diagnostic imaging (DI) database was queried to identify outpatient lithotripsy procedures, as well as inpatient or outpatient surgical procedures not coded in the hospital discharge abstracts. All urological procedures and lithotripsy in Southern Alberta occur at a single site; therefore, these were reliably captured in the Calgary zone administrative data and verified by auditing a $20 \%$ sample of the electronic patient charts. In Alberta, the provincial health system Data Integration Management and Reporting unit oversees the capture, data management, and data quality of all health system data, and in Vancouver, these functions are performed by the VCHA Decision Support Group. Data were managed in accordance with a provincial data transfer agreement involving both health regions.

\section{Outcomes}

Hospital admissions and interventions during the initial ED visit were considered index visit events. Subsequent 
renal colic-related ED visits, admissions, and rescue interventions that occurred after the index visit discharge, but within 60 day of the index encounter, were considered outcome events. Rescue events occurring after the index visit discharge were considered proxies for patients in severe distress or failure of an intended management strategy. ${ }^{20,27}$ Our primary outcome was the occurrence of hospitalization or intervention (ureteroscopy, stenting, nephrostomy, or extracorporeal shock wave lithotripsy [ESWL]) during the study period. Secondary outcomes included index visit hospitalization and intervention rates, 60-day ED revisits, hospitalizations, and rescue interventions stratified by city. Many patients had scheduled procedures (i.e., cystoscopy for stent removal) arising from studyrelated interventions. These were tabulated, but not reported, and were not considered rescue procedures or outcome events.

\section{Sample size}

Based on prior data, ${ }^{23}$ we estimated that $25 \%$ of the patients would require readmission or intervention within 60 days. We determined that 1091 patients per group would provide $80 \%$ power to detect a difference of $5 \%$ in 60 -day event rates between cities, at a $95 \%$ confidence level. For convenience reasons, and to increase the precision of secondary outcome estimates, we analyzed a full year of data from both cities.

\section{Analysis}

Descriptive analyses were performed using means ( \pm standard deviation [SD]), medians (interquartile range $[\mathrm{IQR}]$ ) or proportions, with estimated differences and $95 \%$ confidence intervals (CI) as appropriate. Observed differences in patient characteristics were assessed using t-tests or Wilcoxon rank sum tests. Observed differences in ED revisit rates, admissions, procedures, and other categorical outcomes were assessed using Pearson's chi-squared test or Fisher's exact test, as appropriate. Analysis of variance (ANOVA) or Kruskal-Wallis tests were used to evaluate parametric or non-parametric multiple group comparisons. For non-normally distributed data, we used bootstrap methods (resampling with replacement) to recreate sampling distributions and estimate median differences and related CIs. We applied a permutation test to generate the null distribution of hypotheses and compute empirical $p$ values for these comparisons.

We evaluated our primary outcome and the need for hospital admission or intervention during the study period, using a time to event analysis. Events were plotted on Kaplan-Meier curves, and hazard ratios (95\% CI) were generated using the Vancouver cohort as the reference group. Patients who did not have an outcome event during the 60-day follow-up were censored at that time. We used Cox proportional hazards models to adjust for differences in key covariates including patient age, sex, city, stone size, stone location, the degree of hydronephrosis, triage acuity level, index visit length of stay, and interactions between stone size and location. Statistical analyses were conducted using the $\mathrm{R}$ statistical package (the R Foundation for Statistical Computing; http:// www.R-project.org/).

\section{RESULTS}

During the study year, 4902 in-region patients were seen with an index ED diagnosis of renal colic (Figure 1). Of these, 3105 (63.3\%) had a CT at their index visit, and 213 (4.3\%) had a CT within 30 days of their stone episode. Five hundred forty-five (11.1\%) had an ultrasound (US) during their index visit, and 49 $(1.0 \%)$ had a US within 30 days of their stone episode.



Figure 1. Study Flow Sheet.

* Note: Number of imaging studies does not equal number of patients because some patients underwent two or more studies during the index visit or during the study period. 


\begin{tabular}{|c|c|c|c|c|c|c|c|}
\hline & \multicolumn{2}{|c|}{$\begin{array}{c}\text { Calgary } \\
(N=1,959)\end{array}$} & \multicolumn{2}{|c|}{$\begin{array}{l}\text { Vancouver } \\
(N=1,324)\end{array}$} & \multirow[t]{2}{*}{ Diff } & \multirow[t]{2}{*}{$95 \% \mathrm{Cl}$} & \multirow[t]{2}{*}{$p$-value } \\
\hline \multicolumn{5}{|l|}{ Patient characteristics } & & & \\
\hline Mean age in years (SD) & 50.1 & 14.4 & 51.2 & 14.6 & 1.2 & $0.03,2.1$ & 0.04 \\
\hline Male sex, $n(\%)$ & 1,341 & $68.5 \%$ & 963 & $72.7 \%$ & $4.2 \%$ & $1.1,7.5$ & 0.01 \\
\hline EMS arrival, $n(\%)$ & 385 & $19.6 \%$ & 200 & $15.1 \%$ & $4.5 \%$ & $1.9,7.2$ & $<0.001$ \\
\hline Weekday visit, $n(\%)$ & 1,390 & $71.0 \%$ & 920 & $69.5 \%$ & $0.5 \%$ & $-1.8,4.7$ & 0.39 \\
\hline Day visit $06: 00$ to $18: 00, n(\%)$ & 1,179 & $60.2 \%$ & 849 & $64.1 \%$ & $3.9 \%$ & $0.5,7.4$ & 0.02 \\
\hline CTAS $2-3^{*} n(\%)$ & 1,808 & $92.3 \%$ & 1225 & $92.5 \%$ & 0.3 & $-1.7,2.1$ & 0.86 \\
\hline Mean temperature (SD) & 36.4 & 0.52 & 36.7 & 0.33 & 0.3 & $0.27,0.34$ & 0.84 \\
\hline Mean heart rate (SD) & 80.7 & 19.3 & 77.2 & 15.7 & 3.5 & $1.8,5.1$ & $<0.001$ \\
\hline Mean systolic BP (SD) & 142 & 20.6 & 145 & 32 & 3 & $0.07,7.7$ & 0.05 \\
\hline Mean WBC (SD) & 10.3 & 3.4 & 10.0 & 3.6 & 0.3 & $0.03,0.5$ & 0.03 \\
\hline Median creatinine (IQR) & 90 & 89,92 & 96 & 94,98 & 6.0 & $3.0,8.0$ & 0.009 \\
\hline \multicolumn{8}{|l|}{ Stone characteristics } \\
\hline Median length (IQR) & 4.5 & $3.0-6.0$ & 4 & $3.0,6.0$ & 0.5 & $0.0,1.0$ & 0.003 \\
\hline Median width (IQR) & 4 & $3.0-6.0$ & 4 & $3.0,5.0$ & 0 & 0,0 & 1.0 \\
\hline In distal ureter $n(\%)$ & 1,233 & $62.9 \%$ & 856 & $64.6 \%$ & $1.7 \%$ & $-1.7,5.1$ & 0.34 \\
\hline In middle ureter, $n(\%)$ & 200 & $10.2 \%$ & 125 & $9.4 \%$ & $0.8 \%$ & $-1.4,2.9$ & 0.5 \\
\hline In proximal ureter, $n(\%)$ & 518 & $26.4 \%$ & 343 & $25.9 \%$ & $0.5 \%$ & $-2.6,3.7$ & 0.76 \\
\hline \multicolumn{8}{|l|}{ Hydronephrosis } \\
\hline Absent or mild & 1,203 & $62.0 \%$ & 881 & $67.3 \%$ & $5.3 \%$ & $1.9,8.7$ & 0.002 \\
\hline Moderate or severe & 738 & $38.0 \%$ & 429 & $32.7 \%$ & $5.3 \%$ & $1.9,8.7$ & 0.002 \\
\hline Stranding, $n(\%)$ & 1,091 & $55.7 \%$ & 809 & $61.1 \%$ & $5.4 \%$ & $1.9,8.9$ & 0.002 \\
\hline
\end{tabular}

Table 2. Treatment stratified by city

\begin{tabular}{lccccccc} 
Management & \multicolumn{2}{c}{ Calgary $(N=1,959)$} & Vancouver $(N=1,324)$ & Diff & $95 \% \mathrm{Cl}$ & $p$-value \\
\hline Median wait time (IQR) & 70 minutes & 37,120 & 34 minutes & 18,62 & 36 & $30.5-39$ & $<0.001$ \\
Median ED LOS (IQR) & 5.5 hours & $3.8,7.9$ & 4 hours & $2.9,5.5$ & 1.5 & $1.2-1.6$ & $<0.001$ \\
Index admission, $n(\%)$ & 1,089 & $55.6 \%$ & 136 & $10.3 \%$ & $45.3 \%$ & $42.5-48.1$ & $<0.001$ \\
Index intervention, $n(\%)^{*}$ & 1,021 & $52.1 \%$ & 99 & $7.5 \%$ & $44.6 \%$ & $42.0-47.3$ & $<0.001$
\end{tabular}

$\mathrm{Cl}=$ confidence interval; $\mathrm{Diff}=$ difference; $\mathrm{ED}=$ emergency department; $\mathrm{IQR}=$ interquartile range; $\mathrm{LOS}=$ length of stay .

"Index visit interventions occurred during the index visit encounter.

Overall, 3518 (71.8\%) had a US or CT imaging during their index visit, and 3775 (77.0\%) had imaging within 30 days of the index visit and during their stone episode. The number of studies did not equal the number of patients because some patients had two studies during the index visit or study period. Based on a lack of imaging, 1127 patients were excluded. Another 411 patients were excluded because imaging confirmed only isolated intra-renal stones. There were 3283 patients with well-characterized ureteral stones on CT (Table 1). The mean age of the study group was 50.6 years, and slightly more than two-thirds were male. The stone incidence was higher in Calgary, but the age and sex distribution, EMS arrival rates, day and time of arrival, triage acuity level, vital signs, white blood cell counts, and serum creatinine levels were similar. Table 1 shows that the stone length was slightly larger in Calgary, although the width (transverse diameter) was the same. The stone location was similar between cities, with no difference in the proportions of the proximal, middle, or distal ureteral stones. Concerning the subjective stone parameters, Calgary had higher proportions of patients with moderate or severe hydronephrosis $(38.0 \%$ v. $32.7 \%$, respectively), and Vancouver had more patients with peri-renal stranding (61.1\% v. $55.7 \%$, respectively). 
Table 2 shows that the median wait time to see a physician was shorter in Vancouver than Calgary (34 v. $70 \mathrm{~min}$, respectively), as was the ED length of

\begin{tabular}{|c|c|c|}
\hline Parameter ${ }^{*}$ & Hazard ratio (adjusted) & $p$-value \\
\hline City: Calgary & 3.31 & $<0.001$ \\
\hline Proximal stone & 2.95 & $<0.001$ \\
\hline Severe hydronephrosis & 2.67 & $<0.001$ \\
\hline Moderate hydronephrosis & 2.25 & $<0.001$ \\
\hline Mild hydronephrosis & 1.43 & $<0.001$ \\
\hline ED LOS (per hour) & 1.23 & $<0.001$ \\
\hline Stone width (per mm) & 1.11 & $<0.001$ \\
\hline Multiple stones & 1.1 & 0.06 \\
\hline Age (per year) & 1 & 0.08 \\
\hline Peri-renal stranding & 0.92 & 0.14 \\
\hline CTAS 1 & 1.01 & 0.99 \\
\hline CTAS 2 & 0.95 & 0.85 \\
\hline CTAS 3 & 0.88 & 0.62 \\
\hline CTAS 4 & 0.95 & 0.85 \\
\hline
\end{tabular}

stay (4.0 v. 5.5 hours, respectively). The latter finding was related to higher admission rates in Calgary. Patients in Calgary were more likely to be hospitalized than patients in Vancouver $(55.6 \%$ v. $10.3 \%$, respectively) and to undergo urological intervention ( $52.1 \%$ v. $7.5 \%$, respectively) during their index visit. Of the 1089 patients admitted in Calgary, 1021 (93.8\%) had an immediate ureteroscopic procedure. Of the 160 patients admitted in Vancouver, 99 (61.9\%) underwent an immediate intervention, with 87 ureteroscopic procedures and 12 shock wave lithotripsies.

The primary outcome, hospitalization or intervention during the study period, occurred for 1194 patients in Calgary and 414 patients in Vancouver $(60.9 \%$ v. $31.3 \%$, respectively; $p<0.001)$. Table 3 summarizes the adjusted hazard ratios for the determinants of the primary outcome. The strongest predictor (adjusted hazard ratio) was a Calgary visit site (3.31), followed by proximal stone location (2.95), severe hydronephrosis (2.67), moderate hydronephrosis (2.25), mild hydronephrosis (1.43), ED length of stay (LOS) (1.23 per hour), and stone size (1.11 per mm of width). Age, sex, EMS arrival, triage acuity

\begin{tabular}{|c|c|c|c|c|c|c|c|}
\hline \multirow[b]{2}{*}{ ED revisit } & \multicolumn{2}{|c|}{$\begin{array}{c}\text { Calgary } \\
(N=1,959)\end{array}$} & \multicolumn{2}{|c|}{$\begin{array}{l}\text { Vancouver } \\
(N=1,324)\end{array}$} & \multirow[b]{2}{*}{ Diff (\%) } & \multirow[b]{2}{*}{$95 \% \mathrm{Cl}$} & \multirow[b]{2}{*}{$p$-value } \\
\hline & $n$ & $\%$ & $n$ & $\%$ & & & \\
\hline Within 7 days & 356 & 18.2 & 228 & 17.2 & 1.0 & $-1.8,3.7$ & 0.5 \\
\hline 14 days & 429 & 21.9 & 257 & 19.4 & 2.5 & $-0.4,5.4$ & 0.09 \\
\hline 30 days & 516 & 26.3 & 280 & 21.1 & 5.2 & $2.2,8.2$ & $<0.001$ \\
\hline 60 days & 581 & 29.7 & 299 & 22.6 & 7.1 & $4.0,10.2$ & $<0.001$ \\
\hline \multicolumn{8}{|l|}{ Readmission ${ }^{*}$} \\
\hline Within 7 days & 165 & 8.4 & 52 & 3.9 & 4.5 & $2.8,6.2$ & $<0.001$ \\
\hline 14 days & 195 & 10.0 & 63 & 4.8 & 5.2 & $3.4,7.0$ & $<0.001$ \\
\hline 30 days & 249 & 12.7 & 80 & 6.0 & 6.7 & $4.6,8.7$ & $<0.001$ \\
\hline 60 days & 281 & 14.3 & 86 & 6.5 & 7.8 & $5.7,10$ & $<0.001$ \\
\hline \multicolumn{8}{|l|}{ Rescue procedure } \\
\hline Within 7 days & 143 & 7.3 & 127 & 9.6 & 2.3 & $0.3,4.3$ & 0.02 \\
\hline 14 days & 181 & 9.2 & 207 & 15.6 & 6.4 & $4.0,8.8$ & $<0.001$ \\
\hline 30 days & 268 & 13.7 & 288 & 21.7 & 8.0 & $5.3,10.8$ & $<0.001$ \\
\hline 60 days & 349 & 17.8 & 336 & 25.3 & 7.5 & $4.6,10.5$ & $<0.001$ \\
\hline \multicolumn{8}{|l|}{ Any procedure ${ }^{\dagger}$} \\
\hline Within 7 days & 1,134 & 57.9 & 221 & 16.7 & 41.2 & $38.2,44.2$ & $<0.001$ \\
\hline 14 days & 1,158 & 59.1 & 295 & 22.3 & 36.8 & $33.6,40.0$ & $<0.001$ \\
\hline 30 days & 1,177 & 60.1 & 365 & 27.6 & 32.5 & $29.2,35.8$ & $<0.001$ \\
\hline 60 days & 1,183 & 60.4 & 408 & 30.8 & 29.6 & $26.2,32.9$ & $<0.001$ \\
\hline
\end{tabular}


(A)

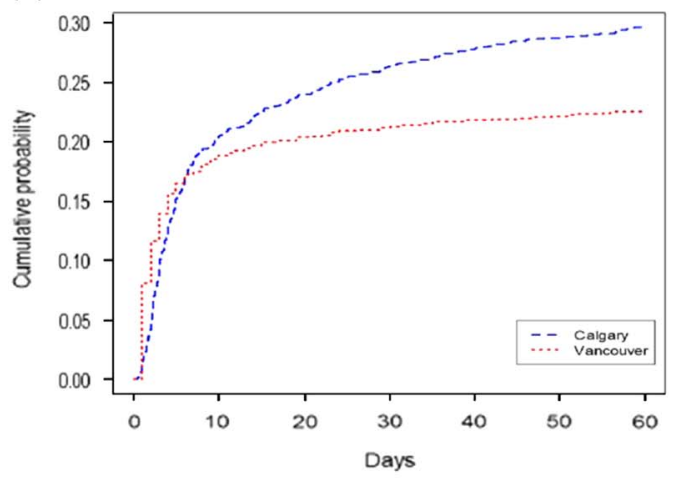

(C)



(B)

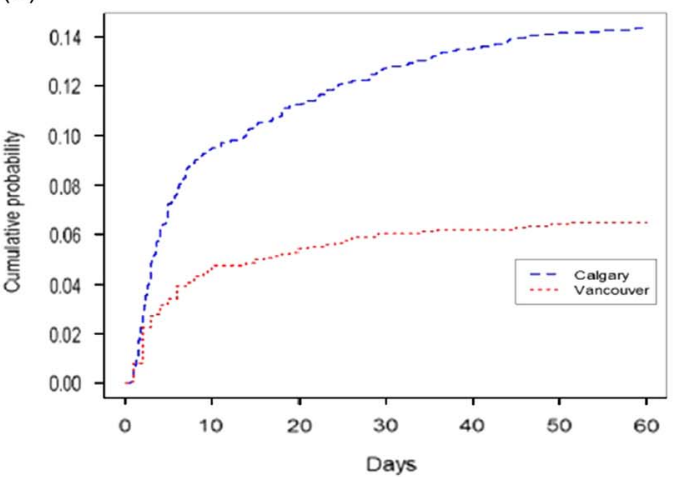

(D)



Figure 2. Sixty-day event rates by city (Kaplan-Meier plots). Figure $2 A$ shows time to renal colic-related ED revisit in days. Figure $2 \mathrm{~B}$ shows time to renal colic-related hospital readmission occurring after discharge from the index ED encounter or hospitalization. Figure $2 \mathrm{C}$ shows time to rescue intervention in days (note that more patients in Vancouver were eligible for an intervention based on low index intervention rates). Figure 2D shows time to intervention for all interventions including those performed during the index encounter.

level, and peri-renal stranding were not associated with the occurrence of hospitalization or intervention.

Table 4 shows that patients in Calgary were more likely to have ED revisits and hospital readmissions during the 60-day follow-up period, despite higher index admission and intervention rates (Figure 2A-B). Figure 2C shows that patients in Vancouver were more likely to undergo a rescue intervention at all time intervals after the index encounter than patients in Calgary (cumulatively, 25.3\% v. $17.8 \%$, respectively). By 60 days, 1183 patients in Calgary (60.4\%) and 408 patients in Vancouver (30.8\%) had undergone a stone intervention. Figure 2D shows that the total number of interventions occurring during the study period was substantially higher in Calgary, inclusive of index interventions.

Table 5 stratifies patients by stone size, showing that $2.3 \%, 51 \%, 26 \%, 14.4 \%$, and $6.3 \%$ of the patients had stone size categories of $<2,2.0-4.9,5.0-6.9,7.0-9.9$, and $\geq 10 \mathrm{~mm}$, respectively. The size distributions were similar in the two cities, but patients in Calgary had more stones in the $7-9.9 \mathrm{~mm}$ category than patients in
Vancouver (16.1\% v. $12.0 \%$, respectively). Figure 3 shows that the Calgary index intervention rates were higher in all stone size categories. Table 5 and Figure 4 indicate that a 60 -day readmission or rescue intervention occurred significantly less often in Vancouver for stones under $5 \mathrm{~mm}$. Conversely, for stones over $5 \mathrm{~mm}$, a 60-day readmission or rescue intervention occurred less often in Calgary, although this finding was tempered by the fact that more patients in Calgary than in Vancouver ( $75 \%$ v. $15 \%$, respectively) with these larger stones had already undergone a stone removal.

\section{DISCUSSION}

This population-based study assessed all patients in two comparable health regions who had an incident renal colic ED visit with a well-characterized ureteral stone during a one-year period. Our data indicated profoundly different management approaches, suggesting a lack of clarity in defining the patient populations who 
Variability of renal colic management and outcomes in two Canadian cities

Table 5. Management and 60-day outcomes stratified by stone size

\begin{tabular}{|c|c|c|c|c|c|c|c|}
\hline \multirow{2}{*}{$\begin{array}{l}\text { Size } \\
<2 \mathrm{~mm} \\
n(\%)\end{array}$} & \multicolumn{2}{|c|}{$\begin{array}{c}\text { Calgary }(N=1,959) \\
n(\%)\end{array}$} & \multicolumn{2}{|c|}{$\begin{array}{c}\text { Vancouver }(N=1,324) \\
n(\%)\end{array}$} & \multirow{2}{*}{$\begin{array}{l}\text { Diff } \\
0.1\end{array}$} & \multirow{2}{*}{$\begin{array}{r}95 \% \mathrm{Cl} \\
-1.0,1.2\end{array}$} & \multirow{2}{*}{$\frac{p \text {-value }}{0.95}$} \\
\hline & 44 & 2.2 & 31 & 2.3 & & & \\
\hline Index intervention & 7 & 15.9 & 1 & 3.2 & 12.7 & $-2.5,27.9$ & 0.13 \\
\hline ED revisit & 10 & 22.7 & 6 & 19.4 & 3.3 & $-18.0,24.7$ & 0.95 \\
\hline Readmission ${ }^{*}$ & 6 & 13.6 & 0 & 0 & 13.6 & $0.7,26.5$ & 0.04 \\
\hline Readmit or intervention ${ }^{*}$ & 6 & 13.6 & 2 & 6.5 & 7.1 & $-8.9,23.3$ & 0.5 \\
\hline $\begin{array}{l}2-4.9 \mathrm{~mm} \\
n(\%)\end{array}$ & 946 & 48.3 & 729 & 55.1 & 6.8 & $3.2,10.3$ & $<0.001$ \\
\hline Index intervention & 282 & 29.8 & 14 & 1.9 & 27.9 & $24.7,31.1$ & $<0.001$ \\
\hline ED revisit & 246 & 26.0 & 134 & 18.4 & 7.6 & $3.5,11.7$ & $<0.001$ \\
\hline Readmission ${ }^{*}$ & 111 & 11.7 & 21 & 2.9 & 8.8 & $6.3,11.4$ & $<0.001$ \\
\hline Readmit or intervention ${ }^{*}$ & 132 & 14 & 73 & 10.0 & 4.0 & $0.7,7.2$ & 0.02 \\
\hline $\begin{array}{c}5-6.9 \mathrm{~mm} \\
n(\%)\end{array}$ & 521 & 26.6 & 333 & 25.2 & 1.4 & $-1.7,4.6$ & 0.38 \\
\hline Index intervention & 355 & 68.1 & 33 & 9.9 & 58.2 & $52.9,63.6$ & $<0.001$ \\
\hline ED revisit & 176 & 33.8 & 97 & 29.1 & 4.7 & $-1.9,11.2$ & 0.18 \\
\hline Readmission ${ }^{*}$ & 89 & 17.1 & 34 & 7.4 & 9.7 & $5.1,14.2$ & $<0.001$ \\
\hline Readmit or intervention ${ }^{*}$ & 129 & 24.8 & 128 & 38.4 & 13.6 & $7.0,20.3$ & $<0.001$ \\
\hline $\begin{array}{l}\text { 7-9.9 mm, } \\
n(\%)\end{array}$ & 315 & 16.1 & 159 & 12.0 & 4.1 & $1.6,6.5$ & 0.001 \\
\hline Index intervention & 270 & 85.7 & 28 & 17.6 & 68.1 & $60.6,75.6$ & $<0.001$ \\
\hline ED revisit & 105 & 33.3 & 50 & 31.4 & 1.9 & $-7.5,11.3$ & 0.76 \\
\hline Readmission & 51 & 16.2 & 20 & 12.6 & 3.6 & $-3.4,10.7$ & 0.37 \\
\hline Readmit or intervention ${ }^{*}$ & 80 & 25.4 & 89 & 56.0 & 30.6 & $21.0,40.1$ & $<0.001$ \\
\hline $\begin{array}{l}\geq 10 \mathrm{~mm} \\
n(\%)\end{array}$ & 133 & 6.8 & 72 & 5.4 & 1.4 & $-0.4,5.4$ & 0.13 \\
\hline Index intervention & 107 & 80.5 & 23 & 31.9 & 48.6 & $34.7,62.3$ & $<0.001$ \\
\hline ED revisit & 44 & 33.1 & 12 & 16.7 & 16.4 & $3.6,29.2$ & 0.02 \\
\hline Readmission $^{*}$ & 24 & 18.0 & 11 & 15.3 & 2.7 & $-8.9,14.4$ & 0.76 \\
\hline Readmit or intervention ${ }^{*}$ & 54 & 40.6 & 51 & 70.8 & 30.2 & $15.7,44.7$ & $<0.001$ \\
\hline
\end{tabular}

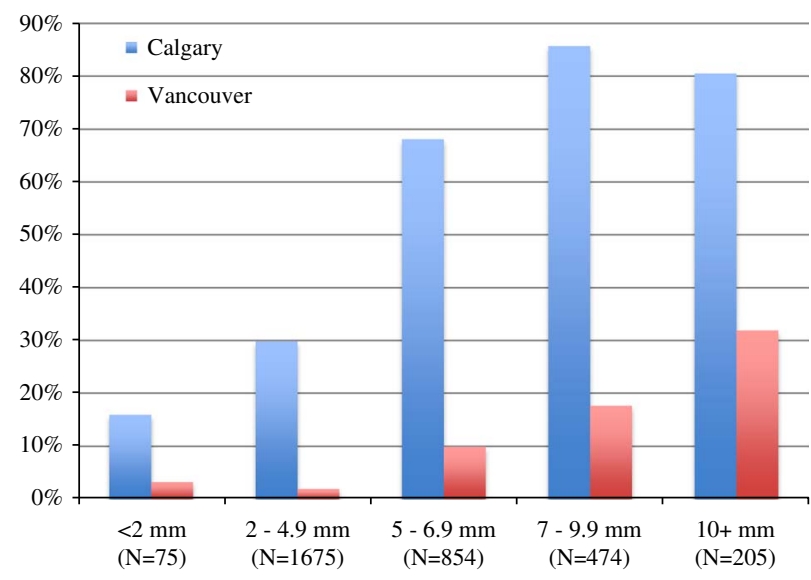

Figure 3. Index visit intervention stratified by stone size.

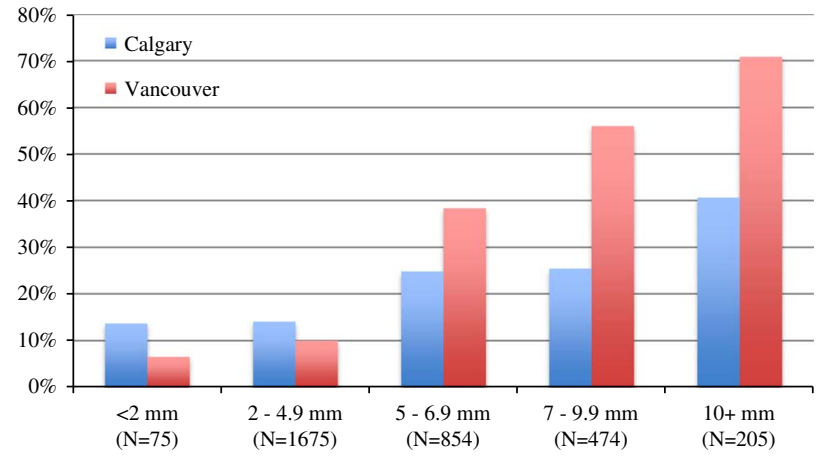

Figure 4. Sixty-day rescue intervention or readmission stratified by stone size. 
would most likely benefit from early intervention, as well as the need for a more standardized approach to referral and intervention. Our analyses were stratified by region rather than by intervention and, therefore, did not clearly define the association between treatment and outcome; however, the data showed that an early interventional approach was associated with a $50 \%$ higher cumulative probability of an ED revisit and double the rates of readmission and intervention.

Higher adverse event rates in a more interventional setting are surprising in that early definitive stone management would be expected to reduce the need for subsequent unplanned ED visits and hospital-based care. It is not surprising to see ED revisit and hospitalization rates of $22.6 \%$ and $6.5 \%$, respectively, in a system in which early intervention rarely occurs. It is surprising to find rates of $29.7 \%$ for ED revisits and $14.3 \%$ for readmission at 60 days in a system (Calgary) that provides early definitive intervention for most patients with significant stones. There are several possible explanations for this finding. During an acute stone episode, many patients have ongoing symptoms. Access to operating room (OR) time is more limited in Vancouver that could have led to inappropriately low rescue intervention rates. Conversely, Calgary has limited access to outpatient urology resources but better access to urgent OR time; hence, urologists may be more likely to "do something" if patients return to EDs with ongoing pain. The observational experience of physicians at the study sites is that patients who return to the hospital after having a stone removal procedure do so as a result of a clot or stent pain, postoperative ureteral edema or spasm causing an obstruction, incomplete stone removal, infection, or even ongoing post-procedural pain that was unexpected (because patients expected the pain to resolve immediately after stone removal). In some cases, access-related difficulties in scheduling stent removal caused patients to reappear in EDs with ongoing stent pain. The ED revisit and readmission rates seen in this study demonstrated that the ureteral stone experience does not always end when the intervention is complete for a variety of reasons. They also highlighted the need for research into optimal stenting practice, notably, patient selection, duration of stenting, discharge education resources, and outpatient follow-up support for stented patients.

The finding of lower rescue intervention rates for patients who had immediate intervention was not surprising. We assumed that patients whose stone had been removed during ureteroscopy had no further need for repeat ureteroscopy unless the stone was incompletely treated. As the stone-free outcomes for modern day ureteroscopy with holmium:YAG lithotripsy and/or a stone basketing approach have been nearly $100 \%$ for ureteral stones, ${ }^{28}$ early intervention would make sense if there were clinical factors that would help predict failure of spontaneous passage. ${ }^{5}$ Our data suggest that current processes for identifying patients who would likely benefit from early intervention are highly variable and imperfect in terms of sensitivity and specificity and that the ideal rate of intervention probably falls between these two divergent practices.

The main finding of this study was that 60-day adverse event rates were not distributed equally across the spectrum of stone sizes. Figure 4 shows that an early interventional approach was associated with higher adverse event rates (readmission or rescue intervention) for the subgroup of patients with stones of $<5 \mathrm{~mm}$ and that a non-interventional approach was associated with higher adverse event rates for patients with stones of $>5$ $\mathrm{mm}$. Prior research also showed an inverse relationship between stone size and spontaneous passage rates, although studies have been limited by a small sample size with broad CIs around passage estimates. Segura et al. reported passage rates of $25 \%-53 \%$ for stones $>5$ $\mathrm{mm}$ and $71 \%-98 \%$ for smaller stones. ${ }^{29}$ Ueno et al. documented an overall $53 \%$ passage rate for 520 patients with ureteral calculi and recommended intervention for stones of $>8 \mathrm{~mm}$ based on size-related passage. ${ }^{30}$ Papa et al. found that a stone size of $>6 \mathrm{~mm}$ was highly associated with the need for intervention, ${ }^{31}$ and a meta-analysis of five studies with a total of 224 patients described passage rates of $47 \%$ for stones of $>5$ $\mathrm{mm}$ and $68 \%$ for smaller stones. ${ }^{6}$ Size alone is not sufficient to predict passage accurately, and stone location may be a more powerful determinant. Coll et al. reported passage rates of $48 \%, 60 \%, 75 \%$, and $79 \%$ for proximal, middle, distal, and ureterovesical (UV) junction stones, respectively, regardless of size. ${ }^{7}$ If size were used as the determinant for intervention, the CT transverse diameter would be the preferred measure, because US examinations can lead to size overestimates, particularly for small stones. ${ }^{32}$

Our findings suggest that an interventional approach leads to better outcomes for stones of $>5 \mathrm{~mm}$, and this finding is relatively robust given the sample size of more than 3000 patients studied in diverse settings. These findings are compatible with recent Canadian guidelines, 
which state that stones of $>5 \mathrm{~mm}$ are less likely to pass spontaneously and that patients with these stones should be counselled on their options. ${ }^{5}$ Our data illustrated substantial practice variability and seemingly high intervention rates in one setting but also show that one-third of patients in the less interventional setting ultimately required stone removal, likely enduring a significant period of potentially avoidable morbidity. Conceptually, the area under the Vancouver Kaplan-Meier plot (Figure 2D) reflects patients who needed an intervention but had not yet had one, and the area between the curves represents patients who had a procedure but would not have done so if they were treated in the alternate setting. Therefore, the higher adverse event rates for patients in Calgary with small stones and higher adverse event rates for patients in Vancouver with large stones suggested that an overly interventional approach for small stones and a non-interventional approach for larger stones were both associated with patient morbidity and that outcome events were driven in part by overtreatment of stones in one setting and undertreatment of stones in the other. If patients who ultimately require intervention could be identified more accurately at the index visit, patient disability could be mitigated using a more specifically targeted intervention.

The outcomes studied, ED visits, hospitalizations, and follow-up procedures were chosen because they were reliably captured in health system data and because the investigators viewed them as proxies for treatment failure. Our premise was that unplanned ED visits and hospital readmissions were indicators of patients in distress and that rescue interventions usually represented a diversion from a chosen path of care or failure of a treatment strategy. However, these outcomes were sometimes driven by factors other than treatment failure. For example, many patients who have had a prior stone removal learned that the treatment for stones was an intervention, not spontaneous passage, and insisted on intervention if they developed another symptomatic stone. Within an interventional culture, many physicians feel that early stone removal is preferable to the uncertainty of spontaneous passage and that intervention is the approach they would want for themselves. In such settings, ED physicians would be more likely to refer marginal patients with smaller stones or even patients with mild to moderate ongoing symptoms who might not require intervention. Such referrals may generate patient expectations for current and future intervention, as well as convey a message to the surgeon that the patient has failed medical management and requires a surgical approach. These patient and physician interactions are less likely in a setting that defaults overwhelmingly to spontaneous passage.

\section{LIMITATIONS}

The most important limitation of this study was that it assessed population-level outcomes, not patient-level responses to a therapeutic strategy. Our outcomes were measures of treatment failure, not treatment success. We did not directly measure stone passage or assess patient experience, quality of life, lost productivity, or symptom severity. It is possible that some patients experienced significant morbidity but did not seek hospital-based care or require intervention during the follow-up period; therefore, the absence of an outcome event does not mean that patients had optimal care or the best possible experience. It is possible that ED revisit rates might relate to differences in primary care access or postdischarge care (e.g., adequacy of analgesic prescription). The findings in this study are applicable to patients with well-characterized ureteral stones; they do not apply to all cases of renal colic or patients with a clinical diagnosis of renal colic. We did not capture outpatient office or clinic visits and cannot comment on the community care that was available, required, or delivered in the two cities. Further, there were undoubtedly patients who did not require hospitalbased care during the 60-day follow-up period but who experienced exacerbations requiring intervention after 60 days; therefore, we cannot say that we captured all outcome events in the two populations. Future studies should assess cost effectiveness and measure patientreported outcomes such as disability, pain, quality of life, and functional status in contrasting systems or interventional approaches.

\section{CONCLUSIONS}

This study demonstrated high variability in the management of ureteral colic and the need for a more standardized approach to referral and intervention. We found that an early interventional approach was associated with higher health system utilization in the form of cumulative ED revisit, hospitalization, and intervention rates. If these events are markers of patient disability, then a less interventional approach to small stones and earlier definitive management of large stones may reduce health system utilization and improve 
outcomes for patients presenting with an index ED visit for acute ureteral colic.

Competing interests: This study was funded by the MSI Foundation.

\section{REFERENCES}

1. Scales CD Jr, Smith AC, Hanley JM, Saigal CS. Urologic Diseases in America Project. Prevalence of kidney stones in the United States. Eur Urol 2012;62(1):160-5.

2. Bensalah K, Tuncel A, Gupta A, et al. Determinants of quality of life for patients with kidney stones. 7 Urol 2008;179(6):2238-43.

3. Saigal CS, Joyce G, Timilsina AR. Urologic Diseases in America Project. Direct and indirect costs of nephrolithiasis in an employed population: opportunity for disease management? Kidney Int 2005;68(4):1808-14.

4. Bryant M, Angell J, Tu H, et al. Health related quality of life for stone formers. 7 Urol 2012;188(2):436-40.

5. Ordon M, Andonian S, Blew B, et al. CUA Guideline: Management of ureteral calculi. Can Urol Assoc 7 2015; 9(11-12):E837-51.

6. Preminger GM, Tiselius HG, Assimos DG, et al. 2007 guideline for the management of ureteral calculi. $\mathcal{F}$ Urol 2007;178(6):2418-34.

7. Coll DM, Varanelli MJ, Smith RC. Relationship of spontaneous passage of ureteral calculi to stone size and location as revealed by unenhanced helical CT. AfR Am 7 Roentgenol 2002;178(1):101-3.

8. Morse RM, Resnick MI. Ureteral calculi: natural history and treatment in an era of advanced technology. 7 Urol 1991; 145(2):263-5.

9. Miller OF, Kane CJ. Time to stone passage for observed ureteral calculi: a guide for patient education. 7 Urol 1999;162(3 Pt 1):688-90.

10. Coursey CA, Casalino DD, Remer EM, et al. ACR Appropriateness Criteria ${ }^{\circledR}$ acute onset flank pain-suspicion of stone disease. Ultrasound Q 2012;28(3):227-33.

11. Teichman JM. Clinical practice. Acute renal colic from ureteral calculus. N Engl 7 Med 2004;350(7):684-93.

12. Brown J. Diagnostic and treatment patterns for renal colic in US emergency departments. Int Urol Nephrol 2006; 38(1):87-92.

13. Sfoungaristos S, Kavouras A, Kanatas P, Duvdevani M, Perimenis P. Early hospital admission and treatment onset may positively affect spontaneous passage of ureteral stones in patients with renal colic. Urology 2014;84(1):16-21.

14. Lindqvist K, Hellström M, Holmberg G, Peeker R, Grenabo L. Immediate versus deferred radiological investigation after acute renal colic: a prospective randomized study. Scand 7 Urol Nephrol 2006;40(2):119-24.

15. Kartal M, Eray O, Erdogru T, Yilmaz S. Prospective validation of a current algorithm including bedside US performed by emergency physicians for patients with acute flank pain suspected for renal colic. Emerg Med 7 2006; 23(5):341-4.
16. Westphalen AC, Hsia RY, Maselli JH, Wang R, Gonzales R. Radiological imaging of patients with suspected urinary tract stones: national trends, diagnoses, and predictors. Acad Emerg Med 2011;18(7):699-707.

17. Smith-Bindman R, Aubin C, Bailitz J, et al. Ultrasonography versus computed tomography for suspected nephrolithiasis. N Engl 7 Med 2014;371(12):1100-10.

18. Hyams ES, Korley FK, Pham JC, Matlaga BR. Trends in imaging use during the emergency department evaluation of flank pain. 7 Urol 2011;186(6):2270-4.

19. Pearle MS, Nadler R, Bercowsky E, et al. Prospective randomized trial comparing shock wave lithotripsy and ureteroscopy for management of distal ureteral calculi. 7 Urol 2001;166(4):1255-60.

20. Hollingsworth JM, Norton EC, Kaufman SR, et al. Medical expulsive therapy versus early endoscopic stone removal for acute renal colic: an instrumental variable analysis. 7 Urol 2013;190(3):882-7.

21. Dauw CA, Kaufman SR, Hollenbeck BK, et al. Expulsive therapy versus early endoscopic stone removal in patients with acute renal colic: a comparison of indirect costs. $7 \mathrm{Urol}$ 2014;191(3):673-7.

22. Rapoport D, Perks AE, Teichman JM. Ureteral access sheath use and stenting in ureteroscopy: effect on unplanned emergency room visits and cost. 7 Endourol 2007;21(9):993-7.

23. Innes GD, Lang E, McRae A, Grafstein EA. Thirty day outcomes after surgical vs. medical management of acute renal colic. Cal f Emerg Med 2015;17:S38-9.

24. Government of Alberta T. Alberta Regional Dashboard. Available at: http://regionaldashboard.alberta.ca/region/ customregion/1197/\#/ (accessed November 11, 2016).

25. Government of British Columbia. BC Population Estimates. Available at: http://bcstats.gov.bc.ca/StatisticsBySubject/ Demography/PopulationEstimates.aspx (accessed October 27, 2016).

26. Fwu CW, Eggers PW, Kimmel PL, Kusek JW, Kirkali Z. Emergency department visits, use of imaging, and drugs for urolithiasis have increased in the United States. Kidney Int 2013;83(3):479-86.

27. Scales CD Jr, Saigal CS, Hanley JM, et al. The impact of unplanned postprocedure visits in the management of patients with urinary stones. Surgery 2014;155(5):769-75.

28. Teichman JM, Rao RD, Rogenes VJ, Harris JM. Ureteroscopic management of ureteral calculi: electrohydraulic versus holmium:YAG lithotripsy. $f$ Urol 1997;158(4): 1357-61.

29. Segura JW, Preminger GM, Assimos DG, et al. Ureteral Stones Clinical Guidelines Panel summary report on the management of ureteral calculi. $\mathcal{F}$ Urol 1997;158(5): 1915-21.

30. Ueno A, Kawamura T, Ogawa A, Takayasu H. Relation of spontaneous passage of ureteral calculi to size. Urology 1977;10(6):544-6.

31. Papa L, Stiell IG, Wells GA, et al. Predicting intervention in renal colic patients after emergency department evaluation. CFEM 2005;7(2):78-86.

32. Ray AA, Ghiculete D, Pace KT, Honey RJ. Limitations to ultrasound in the detection and measurement of urinary tract calculi. Urology 2010;76(2):295-300. 